\title{
Avaliação físico-química e microbiológica da carne soleada do Pantanal
}

\author{
Physicochemical and microbiological evaluation of Pantanal's soleada beef
}

\author{
Larissa Lima ALVES ${ }^{1}$, Ádina Cléia Botazzo DELBEM ${ }^{2}$, \\ Urbano Gomes Pinto de ABREU ${ }^{3}$, Jorge Antonio Ferreira de LARA ${ }^{2 *}$
}

\section{Resumo}

A carne soleada é um produto similar à carne de sol e originária exclusivamente do Pantanal. O objetivo foi avaliar variáveis físico-químicas e microbiológicas da carne soleada produzida em sistema modelo. Foram avaliados os efeitos da utilização dos recursos tecnológicos do congelamento e embalagem a vácuo sobre as variáveis microbiológicas. Prepararam-se amostras usando o corte comercial coxão duro ( $m$. biceps femural) e avaliadas as variáveis de $\mathrm{pH}$, atividade de água, teor de cloretos e perdas de água por pressão, exsudação e cozimento. As contagens de $S$. aureus e E. coli foram realizadas na matéria-prima, carne soleada in natura e carne soleada congelada e embalada a vácuo. Os resultados mostram que a carne soleada precisa de adaptações para que se possa sugerir sua produção em escala. A atividade de água com valor médio de $0,97, \mathrm{pH}$ em 5,72 e teor de cloretos em torno de 2,7\% sugerem um produto com baixa vida de prateleira e que pode ser substrato para microrganismos patogênicos para o homem. O congelamento e a embalagem a vácuo não são recursos adequados para a conservação da carne soleada tradicional.

Palavras-chave: produtos cárneos salgados; segurança do alimento; toxinfecções alimentares.

\begin{abstract}
Soleada beef is similar to sun-dried beef, and it is typical of Pantanal region. The aim of this study was to assess the physicochemical and microbiological variables of soleada beef produced in a model system. The effects of freezing technology resources and vacuum packing on the microbiological variables were assessed. Hence, biceps femoris samples were prepared, and the variables $\mathrm{pH}$, water activity, chloride content, and water loss through pressure, sweating, and cooking were evaluated. The samples were separated into two aliquots; one was analyzed immediately and the other was vacuum packed and frozen. The S. aureus and E. coli count was done in the raw material, soleada beef in natura, and in frozen and vacuum packed soleada beef. Water activity with an average value of 0.97 , pH of 5.72, and chloride content around $2.7 \%$ suggest a product with short shelf life, and which can serve as a substrate for the growth of pathogenic microorganisms, harmful to the human body. Freezing and vacuum packing are not adequate resources for the preservation of the traditional soleada beef.

Keywords: salty meat products; food security; alimentary toxic-infections.
\end{abstract}

\section{Introdução}

A carne soleada é um produto similar à carne de sol e é conhecida em algumas regiões no Pantanal, com suas variações no preparo, como "pranchão", que usa o corte do coxão duro como matéria-prima (m. bíceps femural, predominantemente), 5-6 horas de salga seca com cloreto de sódio, seguida de lavagem com água clorada e secagem em temperatura ambiente por 12-18 horas (COMASTRI, 2006, comunicação pessoal).

O produto é caracterizado pelo baixo tempo de exposição ao cloreto de sódio e secagem durante o seu processamento. De forma geral, pode-se dizer que é obtida na metade do tempo da carne de sol. Neste caso, é um produto que possui menor vida de prateleira, em torno de 2 a 3 dias contra até 4 da carne de sol e meses do charque (SHIMOKOMAKI, 2006, comunicação pessoal). Com isso, a expansão do comércio e do consumo da carne soleada, dependeria de uma vida útil maior e consequentemente de uma mudança no processo de fabricação, transformando a produção artesanal em processo industrial.
Vale ressaltar que as carnes salgadas podem ser uma alternativa para agregar valor à produção de bovinos no Pantanal, normalmente dedicada à cria e cujas matrizes de descarte são abatidas em idade avançada e com carne de baixo valor comercial. A salga, possivelmente, aumentaria o valor agregado desta matéria-prima.

A carne soleada não possui uma regulamentação técnica específica, entretanto, como qualquer produto de origem animal deve atender à regulamentação prevista no Regulamento Industrial de Inspeção de Produtos de Origem AnimalRIISPOA e na legislação da Agência Nacional de Vigilância Sanitária (ANVISA). Assim sendo, apesar de sua elaboração seguir conceitos típicos e regionais, o que agrega valor, o produto necessita também que as suas variáveis físico-químicas e microbiológicas sejam conhecidas de modo a garantir a segurança do consumidor. 
Indesejavelmente, os produtos cárneos salgados podem conter microrganismos patogênicos (LARA et al., 2003) e a presença de $S$. aureus tem sido detectada em amostras de produtos cárneos salgados (SANTANA; AZEREDO, 2005). Os coliformes como, por exemplo, a Escherichia coli, por sua vez, indicadores de higiene no processamento de alimento e índice de contaminação fecal, podem ser resistentes a concentrações suaves de sal (até 5\%) em alimentos (PINTO et al., 2002).

O objetivo deste estudo foi avaliar variáveis físico-químicas e microbiológicas da carne soleada produzida em sistema modelo, no seu formato artesanal. Este tipo de fabricação aborda as técnicas de produção de forma simples, clara e objetiva. É um processo utilizado na elaboração, em pequena escala, de produtos com características regionais próprias.

Foram avaliados os efeitos da utilização dos recursos tecnológicos do congelamento e embalamento a vácuo sobre essas variáveis.

\section{Material e métodos}

\subsection{Obtenção e preparo das amostras}

O experimento foi executado na Embrapa Pantanal, no Laboratório de Alimentos, durante os meses de maio a setembro de 2007.

Foram utilizadas 20 amostras do corte comercial de coxão duro (predominantemente o músculo bíceps femural) de bovinos nelores, fêmeas adultas, obtidas em Corumbá - MS e abatidas e comercializadas conforme as especificações do Serviço de Inspeção Federal. Em cada amostra foram feitos dois cortes laterais e longitudinais de modo a se obter o corte típico do Pantanal chamado pranchão. Cada um dos 20 pranchões foi uma unidade experimental com cerca de 1,6 kg cada.

A preparação das amostras de coxão duro para a fabricação de carne soleada em sistema modelo foram realizadas a partir de uma limpeza do excesso de gordura e tecido conjuntivo, facilitando a penetração do sal no interior das amostras, entretanto, deixando aparente a capa de gordura, uma das características principais da carne soleada.

Cada amostra de 1,6 kg foi dividida em duas partes, uma $(500 \mathrm{~g})$ destinada às análises microbiológicas e físico-químicas da carne in natura e outra $(1,1 \mathrm{~kg})$ destinada à produção da carne soleada em sistema modelo.

\subsection{Produção da carne soleada}

A carne soleada foi preparada conforme os relatos obtidos de indivíduos da comunidade local, que a fabricam de forma artesanal. Para reduzir o efeito da contaminação ambiental e verificar se a salga, o congelamento e a embalagem a vácuo são efetivos no controle do crescimento de $S$. aureus e E. coli, todos os utensílios empregados na fabricação do produto e o cloreto de sódio (sal refinado) foram esterilizados.

Imediatamente, após a retirada da amostragem para a análise microbiológica da matéria-prima, iniciou-se a fabricação da carne soleada. A contaminação da carne soleada pelo ambiente durante o repouso foi minimizada mantendo a carne em ambiente fechado e a superfície previamente sanitizada pelo emprego de água com hipoclorito $2,5 \%$ e ação da luz ultravioleta por 30 minutos. Para minimizar o efeito do manipulador, foram empregadas apenas duas pessoas treinadas na fabricação, usando máscara, toca e luva descartável.

Para o soleamento, utilizou-se o sal refinado, esterilizado a $230^{\circ} \mathrm{C}$ durante 2 horas, na proporção de $3 \%$ em relação ao peso da carne, friccionando manualmente sobre as amostras, metade em cada lado. Essas amostras, em contato com o cloreto de sódio descansaram em temperatura ambiente por 6 horas. Após esse período, todas as amostras foram lavadas com água destilada, para retirada do excesso de sal, e, em seguida, expostas à temperatura ambiente, utilizando-se ganchos metálicos inoxidáveis, espaçados de forma com que houvesse uma circulação homogênea de ar entre as amostras. O tempo de permanência das amostras para a secagem foi de aproximadamente 18 horas após a lavagem. A secagem das amostras foi realizada em uma sala esterilizada, onde foi proibida a entrada das pessoas, para minimizar a contaminação do ambiente.

Parte de cada amostra $(600 \mathrm{~g})$ foi analisada imediatamente, e o restante, $(500 \mathrm{~g})$ embalado a vácuo em embalagens plásticas de polietileno termorresistentes, e mantido sob congelamento $\left(-10{ }^{\circ} \mathrm{C}\right)$ para a repetição das demais análises, após 60 dias de fabricação. As amostras foram descongeladas 24 horas antes da realização das análises posteriores, de modo a ficarem expostas à temperatura ambiente.

\subsection{Análise físico-química}

As análises físico-químicas da carne in natura e soleada foram realizadas nos laboratórios da Embrapa Pantanal, em triplicata.

\section{Análise centesimal}

A determinação da proteína (método de Kjeldahl), extrato etéreo, matéria mineral (cinzas) e cloretos (método Mohr) foram determinados de acordo com a metodologia do Lanara (BRASIL, 1981).

\section{Teor de cloretos}

Para a determinação de cloretos, foram adicionados à matéria mineral 3 gotas de ácido nítrico e $10 \mathrm{~mL}$ de água quente. Essa solução foi filtrada, neutralizada com carbonato de cálcio e aquecida em banho-maria até não haver mais desprendimento de dióxido de carbono. À solução, adicionou-se $1 \mathrm{~mL}$ de cromato de potássio. Após esse procedimento, titulou-se a solução de nitrato de prata $0,1 \mathrm{~N}$ até $\mathrm{o}$ aparecimento de coloração vermelho tijolo (BRASIL, 1981).

\section{Perdas de água}

A perda de água por pressão foi realizada conforme descrito por Souza (2006). Cada amostra de $0,5 \mathrm{~g}$ foi posicionada entre dois papéis filtro (Watman $n^{\circ} 1$ ) e posicionadas entre duas placas quadrangulares de vidro com espessura de $8 \mathrm{~mm}$ cada uma. Sobre este sistema foi colocado um peso de $10 \mathrm{~kg}$ por 5 minutos. A pressão exercida sobre a amostra foi uniforme em toda sua área. Posteriormente, a amostra e os papéis foram pesados e os resultados expressos em porcentagem. 
A perda de água por cozimento foi realizada de acordo com Cason, Lyon e Papa (1997): $70 \mathrm{~g}$ de amostra foram pesadas, embaladas em saco plástico e levadas ao cozimento em banho-maria até que a temperatura interna de cada uma atingisse entre 75 e $80^{\circ} \mathrm{C}$. Após o cozimento, as amostras foram resfriadas até que a temperatura interna estivesse entre $25 \mathrm{e}$ $30^{\circ} \mathrm{C}$. Os resultados foram expressos em porcentagem de perda, determinada pela diferença de peso antes e após o cozimento.

A perda de água por exsudação foi avaliada segundo metodologia proposta por Olivo et al. (2001) modificada: foram pesados $70 \mathrm{~g}$ de cada amostra e, em seguida, acondicionados em bandejas de isopor e recobertos com filme de polietileno. As amostras foram armazenadas por 3 dias a $4{ }^{\circ} \mathrm{C}$ e, ao final deste período, foram pesadas. A perda de água foi estimada pela diferença dos pesos inicial e final e expressa em porcentagem.

$p H$

A leitura do $\mathrm{pH}$ foi realizada em aparelho medidor de $\mathrm{pH}$ (marca Digimed, modelo DMPH/2, São Paulo, Brasil) com eletrodo para carnes (modelo DME/CF1). O pH intramuscular foi avaliado nas carnes in natura, soleada e congelada/embalada a vácuo com leitura por meio de medição direta, calibrado com soluções tampão pH 7,0 e 4,0.

\section{Atividade de água (Aw)}

A atividade de água foi mensurada em equipamento específico (marca Aqualab, modelo CX 2, São Paulo, Brasil) no Laboratório de Ciência e Tecnologia de Alimentos da Universidade Estadual de Londrina, de acordo com Noreña, Hubinger e Menegalli (1986). Este equipamento emprega a técnica de medida de atividade de água através da determinação do ponto de orvalho em espelho resfriado, ou seja, a pressão de vapor da amostra é equilibrada com o espaço vazio da câmara fechada que contém um espelho e resulta na detecção da condensação no espelho. No equilíbrio, a umidade relativa do ar na câmara é igual à atividade de água na amostra, computada a partir da temperatura medida do ponto de orvalho (BRASILEIRA..., 2005).

\subsection{Análise microbiológica}

A análise microbiológica foi realizada com o emprego das membranas Petrifilm ${ }^{\oplus}$, de acordo com as recomendações do fabricante. De cada amostra, $25 \mathrm{~g}$ foram triturados, após adição de $225 \mathrm{~mL}$ de água peptonada 0,1\%, em homogeneizador de amostras (Marca Marconi, modelo MA 440/CF) por 150 segundos e realizada diluição seriada na base 10. Para cada amostra, foi semeado em duplicata em membranas Petrifilm ${ }^{\circledast} 1 \mathrm{~mL}$ da diluição previamente eleita, $10^{-3}$ para $S$. aureus e $10^{-1}$ para E. coli.

As membranas foram incubadas por 24 horas para $S$. aureus e 48 horas para E. coli, conforme especificações do fabricante, e mantidas em estufa a $35^{\circ} \mathrm{C}$.
A contagem de colônias em $S$. aureus foi realizada na área de crescimento circular, considerando o número total de colônias vermelho-violetas (SANTANA; AZEREDO, 2005).

A contagem de colônias de E. coli foi realizada na área de crescimento circular, considerando como E. coli as colônias azuladas, vermelho-azuladas e que produziram gás verificado pela formação de bolhas adjacentes à colônia (SANTANA; AZEREDO, 2005).

A contagem de colônias viáveis corresponde às médias dos valores obtidos em cada uma das duas repetições e expressa em Log UFC.g ${ }^{-1}$ de amostra.

\subsection{Análise estatística}

O delineamento experimental utilizado foi o inteiramente casualizado, com três tratamentos: a) carne in natura, b) carne soleada, e c) carne soleada embalada a vácuo/congelada. As médias foram comparadas pelo teste $t$ de Student e pelo teste Kruskal-Wallis e a correlação entre as variáveis foi obtida pelo método de Pearson com nível de significância de 5\% (ZAR, 1984). O software utilizado foi o SAS (Statistical Analysis System) para Windows versão 8.0.

\section{Resultados e discussão}

\subsection{Variáveis físico-químicas}

Os valores médios de umidade, matéria seca, proteína bruta, extrato etéreo e matéria mineral nas amostras de carne in natura e carne soleada podem ser observados na Tabela 1.

Os valores de umidade, matéria seca, cinzas e gordura diferiram estatisticamente $(\mathrm{p}<0,05)$ para os dois tratamentos. Valores médios de umidade na carne in natura e na carne soleada foram de 74,01 e 69,1\%, respectivamente. Quando avaliada a matéria seca, os valores médios encontrados foram de 25,55 e $30,89 \%$, respectivamente. Os teores médios de cinzas foram de 1,10 e $4,06 \%$ e de gordura, 2,17 e $1,21 \%$, respectivamente, para a carne in natura e carne soleada. Com relação à proteína bruta, os valores encontrados nos dois tratamentos foram de 23,5 e 24,22\%, respectivamente, e não diferiram estatisticamente ( $\mathrm{p}>0,05)$.

A carne soleada apresentou valores superiores de matéria seca, cinzas e proteína em relação à carne in natura e isso reflete a incorporação do cloreto de sódio, a lavagem e forma de dessecação, evidenciando o processo de desidratação que sofreu o produto.

Lira e Shimokomaki (1998) constataram que a carne de sol, de fabricação similar a da carne soleada, apresentou umidade média de $67,88 \%$, variando de 66,33 a 70,10\%. Em contrapartida, Costa e Silva (1999) encontraram oscilações entre 55,70 e $72,50 \%$. Os resultados obtidos para cinzas apresentaram-se em torno de 3,8\%.

Tabela 1. Composição centesimal da carne in natura e da carne soleada.

\begin{tabular}{ccccc}
\hline Tratamentos & Umidade & Matéria seca & Proteína bruta & Extrato etéreo \\
\hline Carne in natura & $74,01( \pm 1,61)^{\mathrm{a}}$ & $25,55( \pm 3,65)^{\mathrm{a}}$ & $23,5( \pm 0,94)^{\mathrm{a}}$ & $2,17( \pm 1,27)^{\mathrm{a}}$ \\
Carne soleada & $69,11( \pm 3,92)^{\mathrm{b}}$ & $30,89( \pm 3,92)^{\mathrm{b}}$ & $24,22( \pm 0,84)^{\mathrm{a}}$ & $1,10( \pm 0,13)^{\mathrm{a}}$ \\
\hline
\end{tabular}

Valores médios em porcentagem em base de Matéria Umida; médias seguidas de mesma letra na coluna não diferem estatisticamente pelo teste $\mathrm{t}(\mathrm{p}>0,05$ ). 
Biscontini et al. (1996) encontraram no jerked beef umidade média de $48,77 \%$, oscilando entre 45,94 e 51,23\%, e cinzas, cujo valor médio foi de 18,43\%, oscilando entre 17,38 e 18,98\%. Correia (2003), realizando um estudo com charque e jerked beef, detectou valores de umidade, cinzas e proteínas entre 45,97 e $51,17 \%, 17,25$ e $18,07 \%$, e 29,26 e $24,95 \%$, respectivamente. No caso do jerked beef, que tem atividade de água em torno de 0,75\% e umidade entre 45 e $50 \%$, tem-se um produto cárneo de umidade intermediária, cuja conservação é medida em meses na temperatura ambiente e embalado a vácuo (PINTO; FRANCO; SHIMOKOMAKI, 1998; LARA et al., 2003). A a carne soleada não pode ser classificada como alimento de umidade intermediária, já que a sua umidade está próxima da própria matéria-prima.

A Tabela 2 apresenta os valores médios de perdas de água por pressão, exsudação e cozimento das carnes avaliadas.

Os diferentes tratamentos influenciaram significativamente nas perdas de água pela carne. As perdas de água por pressão e cozimento foram significativas $(\mathrm{p}<0,05)$ nos tratamentos da carne soleada e carne soleada embalada a vácuo, em relação à carne in natura. Nas perdas por exsudação, nota-se que houve uma diferença significativa $(\mathrm{p}<0,05)$ para a carne embalada a vácuo e congelada $(2,91)$, em relação às carnes in natura $(3,53)$ e soleada $(2,53)$.

De acordo com Pardi et al. (2001), a utilização de cloreto de sal nas carnes soleada, soleada embalada a vácuo e congelada influenciou nas perdas de água. A menor perda de água se deve à extração e solubilização das proteínas miofibrilares da carne pelo sal, e estes processos contribuíram para a emulsificação das gorduras e o aumento da capacidade de retenção de água, reduzindo as perdas por cozimento.

Segundo Silva, Castilho e Ortega (2007), na temperatura de 60 a $70^{\circ} \mathrm{C}$, a rede do tecido conectivo e as fibras musculares contraem-se de modo conjunto e longitudinal, e a extensão deste encolhimento aumenta com a temperatura. Em consequência, tem-se uma grande perda de água que ocorre no cozimento.

A atividade de água (Aw) e o teor de cloretos determinados na carne soleada foram de 0,97 e 2,71, respectivamente. Esta alta Aw é compatível com a quantidade de cloreto de sódio utilizada no processamento da carne soleada. A carne de sol, por exemplo, apresenta Aw em torno de 0,898 a 0,967. Com relação aos cloretos, Costa e Silva (1999) detectaram variações entre 2,90 e 11,90 para a carne de sol. Estes resultados mostram a variação no valor deste parâmetro que pode ocorrer em

Tabela 2. Valores médios de perdas de água por pressão, exsudação e cozimento em carnes bovina com diferentes preparos.

\begin{tabular}{lccc}
\hline $\begin{array}{c}\text { Perdas de água } \\
(\%)\end{array}$ & $\begin{array}{c}\text { Carne } \\
\text { in natura }\end{array}$ & $\begin{array}{c}\text { Carne } \\
\text { soleada }\end{array}$ & $\begin{array}{c}\text { Carne soleada } \\
\text { embalada a } \\
\text { vácuo/congelada }\end{array}$ \\
\hline Perdas por pressão & $27,62( \pm 8,14)^{\mathrm{b}}$ & $19,56( \pm 6,41)^{\mathrm{a}}$ & $17,24( \pm 7,55)^{\mathrm{a}}$ \\
Perdas por exsudação & $17,24( \pm 7,55)^{\mathrm{a}}$ & $2,53( \pm 0,63)^{\mathrm{a}}$ & $2,91( \pm 0,88)^{\mathrm{b}}$ \\
Perdas por cozimento & $31,13( \pm 5,87)^{\mathrm{b}}$ & $25,85( \pm 5,86)^{\mathrm{a}}$ & $24,08( \pm 4,83)^{\mathrm{a}}$ \\
\hline $\begin{array}{l}\text { Médias seguidas de mesma letra na linha não diferem estatisticamente pelo teste t } \\
(\mathrm{p}>0,05)\end{array}$
\end{tabular}

produtos fabricados de forma artesanal dependendo de vários fatores, como peculiaridades regionais e manipulador.

Costa e Silva (1999) descreveram que, muitas vezes, produtos salgados de umidade elevada, como é o caso da carne soleada, não são expostos ao sol para a secagem e, quando isto acontece, a exposição é feita no início da manhã ou no final da tarde, por período relativamente curto, insuficiente para provocar desidratação do produto. Os resultados de Aw encontrados por Lira e Shimokomaki (1998) na carne de sol $(0,92)$ evidenciam que se trata de um produto cárneo levemente salgado, parcialmente desidratado e apenas semipreservado pela salga e possui uma vida de prateleira muito curta, comparada a do jerked beef e do charque (SHIMOKOMAKI et al., 1998).

A Tabela 3 apresenta o coeficiente de correlação entre as variáveis analisadas na carne soleada.

Os dados da Tabela 3 mostram que há uma correlação negativa e significativa entre a umidade e cloretos $(r=-0,52)$, e entre a Aw e cloretos $(r=-0,42)$, indicando que, quanto maior a adição de cloretos, menor é a umidade e a atividade de água do produto. Esses dados confirmam estudo realizado por Ambiel (2004) que mostrou que, quanto maior a adição de cloreto de sódio (4\%) na carne de sol, maior é a perda de peso da carne e menores serão os valores de umidade e atividade de água $(0,958)$.

Entretanto, Carvalho Junior et al. (2001) encontraram um valor de atividade de água de 0,96 para a carne de sol com adição de $4 \%$ de sal. Outros parâmetros estão correlacionados com a Aw dos produtos cárneos, entre eles, pode-se citar a proteína que obteve uma correlação negativa $(r=-0,22)$ e não diferiu significativamente $(\mathrm{p}>0,05)$ com a variável atividade de água.

Sabadini et al. (2001) estudou a contribuição das proteínas no valor de Aw em carnes salgadas por meio da comparação com soluções de cloreto de sódio. Ele verificou que, à medida que a umidade decresce, aumenta a proporção relativa das proteínas e que a Aw diminui mais intensamente nas carnes do que nas soluções salinas em temperatura de 10 e $20^{\circ} \mathrm{C}$ e explica que tal fato é devido às interações da água com a matriz proteica da carne.

Os valores médios de $\mathrm{pH}$ das carnes in natura, soleada $\mathrm{e}$ soleada embalada a vácuo e congelada foram respectivamente 5,$65 ; 5,72 ; \mathrm{e} 5,54$. Os valores de $\mathrm{pH}$ nas carnes foram semelhantes entre si, não sofrendo alteração no processo da salga, porém,

Tabela 3. Coeficiente de correlação (r) entre as variáveis da carne soleada.

\begin{tabular}{lccccccc}
\hline Variáveis & Cloretos & Umidade & Cinzas & Proteína Gordura & $\mathrm{Aw}^{1}$ & $\begin{array}{c}\mathrm{pH} \\
\text { total }\end{array}$ \\
\hline Cloretos & 1 & - & - & - & - & - & - \\
Umidade & $-0,52^{*}$ & 1 & - & - & - & - & - \\
Cinzas & $0,98^{*}$ & $-0,74^{*}$ & 1 & - & - & - & - \\
Proteína & 0,11 & $-0,36^{*}$ & $0,26^{*}$ & 1 & - & - & - \\
Gordura & $0,19^{*}$ & 0,07 & $-0,31^{*}$ & $0,20^{*}$ & 1 & - & - \\
Aw & $-0,42^{*}$ & $-0,15$ & $-0,39^{*}$ & $-0,22^{*}$ & $-0,27^{*}$ & 1 & - \\
pH total & $-0,07$ & $-0,09$ & 0,11 & $-0,06$ & $-0,10$ & $0,21^{*}$ & 1 \\
\hline 1atividade de água ${ }^{*} \mathrm{p}>0,05$ & & & & & &
\end{tabular}

${ }^{1}$ atividade de água; ${ }^{*} \mathrm{p}>0,05$. 
estatisticamente, esses valores apresentaram diferença $(p<0,05)$ entre os tratamentos.

\subsection{Variáveis microbiológicas}

As médias de resultados obtidos nas análises microbiológicas estão apresentadas na Tabela 4.

$\mathrm{Na}$ Tabela 4, observa-se que, mesmo com o emprego das tecnologias de salga, embalagem a vácuo e congelamento, ainda foi possível recuperar células viáveis de $S$. aureus e E. coli no substrato, concordando com Leitão (1985) que afirma que é possível a recuperação dos microrganismos após a injúria celular se as condições adequadas para o seu desenvolvimento voltem a ocorrer no substrato. Apesar do emprego do vácuo e congelamento inibirem o crescimento microbiológico e aumentarem a vida de prateleira dos produtos cárneos, o risco da ocorrência de toxinfecções não pode ser desconsiderado, aumentando assim a importância da manipulação higiênica da matéria-prima e dos produtos processados (LARA et al., 2001).

Foi possível verificar que a contagem de $S$. aureus aumentou cerca de dez vezes na carne soleada após a manipulação, salga e período de repouso em temperatura ambiente. Isto pode ter ocorrido pelas características desta bactéria que tolera concentrações salinas na faixa de 3\%, como a encontrada na carne soleada. A Aw em 0,97 não é capaz de ser uma barreira ao crescimento de $S$. aureus, que tolera Aw em até 0,86 , sem produzir toxina nestes casos (BAIRD-PARKER, 1990).

O S. aureus se torna um bom competidor em ambientes com concentrações salinas um pouco acima do encontrado na matéria-prima (PINTO; FRANCO; SHIMOKOMAKI, 1998; SENIGALIA, 1999), como é o caso da carne soleada, pois a diminuição da capacidade de crescimento de outras bactérias faz com que haja maior oferta de nutrientes para o seu crescimento no substrato.

Os resultados encontrados para $S$. aureus estão acima do tolerável $\left(3,7\right.$ Log UFC. g $\left.^{-1}\right)$ pelos parâmetros adotados pela Agência Nacional de Vigilância Sanitária (BRASIL, 2001), sugerindo a inadequação da carne soleada para a venda em escala comercial, pelo menos na forma que é feita atualmente. As manipulações higiênicas da matéria-prima e do produto final podem ser alternativas para reduzir a contagem de $S$. aureus (LARA et al., 2003).

Entretanto, neste experimento, a carne soleada foi elaborada em sistema modelo, no qual o sal e os utensílios de fabricação estavam esterilizados, indicando que a contaminação pode ser maior ainda no alimento produzido artesanalmente.

De acordo com estes resultados, o valor médio de cloretos encontrado na carne soleada $(2,71)$ é insuficiente para reduzir a

Tabela 4- Contagem de S. aureus e E.coli nos diferentes tratamentos.

\begin{tabular}{cccc}
\hline $\begin{array}{c}\text { Variáveis } \\
\left(\text { Log } U F C . g^{-1}\right)\end{array}$ & $\begin{array}{c}\text { Carne } \\
\text { in natura }\end{array}$ & $\begin{array}{c}\text { Carne } \\
\text { soleada }\end{array}$ & $\begin{array}{c}\text { Carne soleada embalada } \\
\text { a vácuo/congelada }\end{array}$ \\
\hline S. aureus & 4,43 & 5,23 & 4,41 \\
E. coli & 2,05 & 1,83 & 0,90 \\
\hline
\end{tabular}

atividade de água e consequentemente não exerce ação inibidora significativa no desenvolvimento de bactérias Gram-positivas, como a S. aureus. Costa e Silva (2001) citam que o S. aureus é formado por organismos com características seletivas que o torna favorecido frente às outras bactérias, cresce e produz enterotoxina em baixos valores de atividade de água. São halotolerantes, crescem em até $15 \%$ de sal, podendo representar um perigo adicional, pela diminuição de microrganismos competidores.

Costa e Silva (2001) realizaram um estudo com amostras de carne de sol em estabelecimentos inspecionados e constataram que a média da contagem de $S$. aureus foi superior a 5,0 Log UFC. $\mathrm{g}^{-1}$, representando risco da presença de enterotoxina suficiente para desencadear a intoxicação alimentar.

Para produtos similares à carne soleada e à carne de sol, Shimokomaki et al. (1998) estudaram os parâmetros relacionados ao charque e observaram valores para atividade de água entre 0,70 e 0,75. Lara et al. (2003) observaram que nesses parâmetros de Aw, durante o processamento do charque, $S$. aureus foi capaz de sobreviver às etapas de salga. Entretanto, na etapa após a secagem ao sol, houve uma redução acentuada na contagem de S. aureus.

Os valores encontrados para a contagem de E. coli se mantiveram no limite do permitido pela Legislação Federal (3,0 Log UFC.g g $^{-1}$, conforme a resolução RDC no 12 (BRASIL, 2001). Estes resultados mostram que a $E$. coli não teve um crescimento na carne soleada, inclusive sofrendo uma redução de células viáveis após o processo de soleamento. No caso de charque e produtos similares, a baixa disponibilidade de água é o fator principal para inibir E. coli, entretanto, na carne soleada, a disponibilidade ainda é elevada $(0,968)$, próxima a 0,99 da carne in natura.

A embalagem a vácuo e o congelamento tiveram um efeito positivo para a redução dos microrganismos estudados, reduzindo em três vezes a contagem de $S$. aureus e cerca de seis vezes a de $E$. coli. Mas mesmo assim, a presença de $S$. aureus continuou acima do permitido pela legislação. Ademais, a toxina produzida pelo estafilococo é termorresistente, continuando no alimento após a morte da bactéria (SENIGALIA, 1999). Neste caso, a prevenção da contaminação excessiva durante a manipulação é fundamental para a segurança dos alimentos.

Os valores de $\mathrm{pH}$, Aw e teor de cloretos, em nenhuma etapa do processamento da carne soleada, foram fatores efetivos de inibição para o crescimento de microrganismos. Contrariamente, Sperber (1983) e Jay (2000) afirmam que a sinergia desses fatores de crescimento pode inibir o crescimento dos microrganismos se empregados na medida certa. Leistner (1985) define através da teoria da tecnologia dos obstáculos que o emprego de um único fator para inibir microrganismos não é o suficiente para garantir efetividade no controle e que a combinação de mais de um fator, no mínimo, se faz necessário.

De acordo com Franco e Landgraf (1996), assim como ocorre com a atividade de água, os microrganismos têm valores de pH mínimo, ótimo e máximo para a sua multiplicação. $\mathrm{O}$ pH ótimo para a multiplicação de E. coli e $S$. aureus está entre 6,0 e 8,0 e 6,0 e 7,0 respectivamente. Desta forma, como na maioria 
dos produtos cárneos, o $\mathrm{pH}$ não foi um fator limitante para o desenvolvimento microbiológico na carne soleada.

Em relação à carne soleada como é feita hoje, recomendase o emprego da embalagem a vácuo, pois além de não inibir efetivamente E. coli e $S$. aureus, o risco de germinação, crescimento e produção de toxina por Clostridium botulinum é real (LARA et al., 1999, 2003).

\section{Conclusões}

A carne soleada em sua produção tradicional não é um produto cárneo de umidade intermediária e, desta forma, possui uma vida de prateleira curta, em torno de dois dias, contra quatro dias da carne de sol e meses do charque.

A combinação de $\mathrm{pH}$, atividade de água e teor de cloretos não foi suficiente para inibir o crescimento de $S$. aureus e E. coli.

O emprego do vácuo e o do congelamento também não foi suficiente para controlar o desenvolvimento de microrganismos patogênicos na carne soleada.

\section{Referências bibliográficas}

AMBIEL, C. Efeito das concentrações combinadas de cloreto e lactato de sódio na conservação de um sucedâneo da carne-de-sol. 2004. $101 \mathrm{f}$. Tese (Doutorado)-Faculdade de Engenharia de Alimentos, Universidade Estadual de Campinas, Campinas, 2004.

BAIRD-PARKER, A. C. The Staphylococci: an introduction. Journal Applied Bacteriology, Supplement, p.1S-8S, 1990.

BISCONTINI, T. M. B. et al. An ultrastuctural observation on charquis, salted, intermediate moisture meat products. Meat Science, v. 43, n. 4, p. 351-358, 1996.

BRASIL. Agência Nacional de Vigilância Sanitária - ANVISA. Resolução RDC no 12 de 2 de janeiro de 2001. Diário Oficial da União, Brasília, DF, 10 jan. 2001.

BRASIL. Ministerio da Agricultura, Pecuaria e Abastecimento. Laboratório Nacional de Referencia Animal - LANARA. Portaria n. 001/81, de 07 de outubro de 1981. Métodos Analíticos Oficiais para Controle de Produtos de Origem Animal e seus Ingredientes. Diário Oficial da União, Brasília, DF, 13 out. 1981. seção 1, p. 19381.

BRASILEIRA DE EQUIPAMENTOS LTDA - BRASEQ. Manual de instruções de operação: analisador de atividade de água Aqualab Decagon. [S. 1.], 2005.

CARVALHO JUNIOR, B. C. et al. Alterações da atividade de água e da cor da carne no processo de elaboração da carne salgada desidratada. Ciência e Tecnologia de Alimentos, v. 21, p. 14-19, 2001.

CASON, J. A.; LYON, C. E.; PAPA, C. M. Effect of muscle opposition during rigor on development of broiler breast meat tenderness. Poultry Science, v. 76, p. 725-787, 1997.

CORREIA, P. T. R. Influência da dessalga e cozimento sobre a composição química e perfil de ácidos graxos de charque e jerked beef. Ciência e Tecnologia de Alimentos, v. 1, n. 23, p. 38-42, 2003.

COSTA, L. E.; SILVA, A. J. Avaliação microbiológica da carne-desol elaborada com baixos teores de cloreto de sódio. Ciência e Tecnologia de Alimentos, v. 21, n. 2, p. 149-135, 2001.

COSTA, L. E.; SILVA, A. J. Qualidade sanitária da carne de sol comercializada em açougues e supermercados de João Pessoa - PB. Boletim CEPPA, v. 17, n. 2, p. 137-144, 1999.

FRANCO, B. M. D. G.; LANDGRAF, M. Microbiologia dos alimentos. São Paulo: Atheneu, 1996.
JAY, Y. M. Modern food microbiology. $6^{\text {th }}$ ed. Garthersburg: Aspens Publishers, 2000.

LARA, J. A. F. et al. Botulismo: riscos decorrentes do processamento inadequado de alimentos. O charque como enfoque. Higiene Alimentar, v. 13, n. 66, p. 52-62, 1999.

LARA, J. A. F. et al. Evaluation of Survival of Staphylococcus aureus and Clostridium botulinum in Charqui Meats. Meat Science, v. 65, n.1, p. 609-613, 2003.

LARA, J. A. F. et al. Sistemas de embalagens para carnes frescas e processadas. Revista Nacional da Carne, v. 25, n. 293, p. 46-52, 2001.

LEISTNER, L. Hurdle technology applied to meat products of the shelf stable products and intermediate moisture foods types. In: MULTON, J. L. (ed.). Properties of water in foods. Dordrecht: Martinus Niyhoff, p. 309-329, 1985.

LEITÃO, M. F. A injúria microbiana e sua importância na avaliação da qualidade microbiológica dos alimentos. Boletim do Ital, v. 22, n. 4, p. 397-416, 1985.

LIRA, G. M.; SHIMOKOMAKI, M. Parâmetros de qualidade da carne de sol e dos charques. Higiene Alimentar, v. 44, n. 13, p. 66-69, 1998.

NOREÑA, C. Z.; HUBINGER, M. D.; MENEGALLI, F. C. Técnicas básicas de determinação de atividade de água. Boletim SBCTA, v. 30, n. 1, p. 91-96, 1986.

OLIVO, R. et al. Dietary vitamin E inhibits poutry PSE and improves meat functional proprieties. Journal of Food Biochemistry, v. 25, n. 4, p. 271-283, 2001.

PARDI, M. C. et al. Ciência, higiene e tecnologia da carne. 2. ed. Goiânia: UFG, 2001.

PINTO, M. F. et al. Charqui meats and fermented meat products: role of bacteria for some sensorial developement. Meat Science, v. 61, p. 187-191, 2002.

PINTO, M. F.; FRANCO, B. D. G. M.; SHIMOKOMAKI, M. Controle de Staphylococcus aureus em charques (jerked beef) por culturas iniciadoras. Ciência e Tecnologia de Alimentos, v. 18, p. 200-204, 1998.

SABADINI, E. et al. Alteração da atividade de água e da cor da carne no processo de elaboração da carne salgada desidratada. Ciência e Tecnologia de Alimentos, v. 21, n. 1, p. 14-19, 2001.

SANTANA, A. S.; AZEREDO, D. R. P. Comparação entre o sistema Petrifilm RSA e a metodologia convencional para a determinação de estafilococos coagulase posistiva em alimentos. Ciência e Tecnologia de Alimentos, v. 25, n. 3, p. 121-125, 2005.

SENIGALIA, S. W. B. Estudo da presença de Staphylococcus aureus em charque e sua capacidade de sobreviver durante o processamento. 1999. 71 f. Dissertação (Mestrado)-Centro de Ciências Agrárias, Universidade Estadual de Londrina, Londrina, 1999.

SHIMOKOMAKI, M. et al. Charqui meats are hurdle technology meat products. Food Review International, v. 14, p. 339-349, 1998.

SILVA, L. E.; CASTILHO, J. C.; ORTEGA, M. M. E. Efeito do cozimento na qualidade do músculo semitendinoso. Ciência e Tecnologia de Alimentos, v. 27, n. 3; p. 441-445, 2007.

SOUZA, H. B. A. Parâmetros físicos e sensoriais utilizados para avaliação de qualidade da carne de frango. In: SEMINÁRIO INTERNACIONAL DE AVES E SUÍNOS, 5., 2006, Florianópolis. Anais....

SPERBER, W. H. Influence of water activity on foodborne bactéria - a review. Journal of Food Protection, v. 46, n. 2, p. 142-150, 1983.

ZAR, J. H. Biostatistical analysis. 2. ed. New Jersey: Prentice Hall, 1984. 